\title{
Secretory pattern of inhibin A, inhibin B and inhibin pro-aC during induced follicular atresia and subsequent follicular development in the golden hamster (Mesocricetus auratus)
}

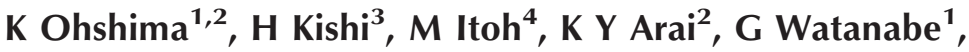 \\ K Arai $^{2}$, K Uehara ${ }^{2}$, N P Groome ${ }^{5}$ and K Taya ${ }^{1}$ \\ ${ }^{1}$ Laboratory of Veterinary Physiology, Tokyo University of Agriculture and Technology, 3-5-8 Saiwai-cho, Fuchu, Tokyo 183-8509, Japan \\ ${ }^{2}$ Department of Tissue Physiology, Tokyo University of Agriculture and Technology, 3-5-8 Saiwai-cho, Fuchu, Tokyo 183-8509, Japan \\ ${ }^{3}$ Department of Animal Reproduction, National Institute of Animal Industry, Ibaraki, 305-0991, Japan \\ ${ }^{4}$ Primate Research Institute of Animal Industry, Ibaraki, 305-9001, Japan \\ ${ }^{5}$ School of Biological and Molecular Sciences, Oxford Brookes University, Headington, Oxford OX3 0BP, UK \\ (Requests for offprints should be addressed to K Taya; Email: taya@cc.tuat.ac.jp)
}

\begin{abstract}
The changes in plasma concentrations of inhibins A, B and pro- $\alpha \mathrm{C}$ were determined in the cyclic golden hamster during follicular atresia induced with antiserum against luteinizing hormone releasing hormone (LHRH-AS) at $1100 \mathrm{~h}$ on day 4 (day $1=$ day of ovulation). Follicular status in the ovary was also studied by determining the number of follicles ovulating in response to human chorionic gonadotrophin (hCG) injection. The time-courses of changes in plasma concentrations of inhibins A, B and pro- $\alpha \mathrm{C}$ were different from each other during induced follicular atresia and subsequent follicular development. Plasma concentrations of inhibin A decreased to $58.6 \%$ of initial values by $24 \mathrm{~h}$ after LHRH-AS treatment, and then remained relatively low until at least $60 \mathrm{~h}$ later. Plasma concentrations of inhibin B decreased to $64 \cdot 2 \%$ of the initial values by $18 \mathrm{~h}$ after LHRH-AS treatment and remained at basal values for $36 \mathrm{~h}$, but increased abruptly to greater than initial values at $42 \mathrm{~h}$ after the treatment. Plasma concentrations of inhibin pro- $\alpha \mathrm{C}$ increased at
\end{abstract}

6 and $12 \mathrm{~h}$, decreased suddenly to $21.9 \%$ of the initial values by $24 \mathrm{~h}$ after LHRH-AS treatment, and then gradually increased until $60 \mathrm{~h}$ after LHRH-AS. The number of follicles responding to hCG decreased gradually between 0 and $30 \mathrm{~h}$ after LHRH-AS, when no ovulations were observed, and then gradually increased until $60 \mathrm{~h}$. The changes in follicular ovulatory responses to hCG correlated with the plasma profile of inhibin A throughout the experiment. These results suggest that inhibin A is mainly secreted by large antral follicles. In contrast, during the subsequent follicular development, the plasma concentration of inhibin B increased earlier than that of inhibin A. These results suggest that inhibin B is secreted by small and large antral follicles. Plasma concentrations of inhibin pro- $\alpha \mathrm{C}$ were high at a time when plasma concentrations of oestradiol-17 $\beta$ had already decreased, indicating that inhibin pro- $\alpha \mathrm{C}$ is secreted not only from healthy follicles but also from early atretic antral follicles.

Journal of Endocrinology (2002) 172, 575-581

\section{Introduction}

Inhibin is a glycoprotein hormone secreted from granulosa cells of the ovarian follicles in female animals and is a key factor for determining species-specific ovulation rates through the regulation of follicle-stimulating hormone (FSH) secretion (Kishi et al. 1996, 1997a,b, Taya \& Watanabe 1999). We have previously shown that inhibin bioactivity in ovarian venous plasma decreased gradually during the process of follicular atresia, whereas concentrations of oestradiol-17 $\beta$ declined quickly after hypophysectomy at $1100 \mathrm{~h}$ on the day of pro-oestrus in the rat (Kaneko et al. 1987). We have also previously demonstrated that granulosa cells continue to secrete immuno- reactive inhibin during the process of follicular atresia in the hamster (Otsuka et al. 1997). However, the time-courses of plasma concentrations of inhibin A and inhibin $\mathrm{B}$ during induced follicular atresia are not known. Recently, a new enzyme-linked immunosorbent assay (ELISA) has been developed (Groome \& Lawrence 1991, Groome et al. 1995, 1996) that has been adapted to the specific measurement of different circulating forms of inhibins. In another previous study, we investigated the pattern of plasma concentrations of inhibins A, B and pro- $\alpha \mathrm{C}$ during the normal oestrous cycle of the female golden hamster (Ohshima et al. 1999) and noted significant negative relationships between plasma FSH and both dimeric inhibins from day 1 to day 3 , together 
with significant positive relationships between plasma oestradiol-17 $\beta$ and inhibin A or inhibin pro- $\alpha \mathrm{C}$, but no significant relationship between plasma oestradiol-17 $\beta$ and inhibin B throughout the oestrous cycle.

In the present study, relationships between circulating inhibins (A, B and pro- $\alpha \mathrm{C}$ ) and ovarian follicular activity were studied during induced follicular atresia and subsequent follicular development induced by immunoneutralization of luteinizing hormone (LH) releasing hormone (LHRH). Relationships between circulating FSH and each inhibin molecule were also investigated in this present model.

\section{Materials and Methods}

Animals

Adult female golden hamsters (Mesocricetus auratus) were maintained under controlled temperature and lighting (lights on from $0500 \mathrm{~h}$ to $1900 \mathrm{~h}$ ). Food and water were available ab libitum. The 4-day oestrous cycle was determined by the presence of a characteristic vaginal discharge on the morning of the day of ovulation, which was designated day 1 of the cycle. Hamsters with at least two consecutive 4-day oestrous cycles were used in this study.

\section{Antiserum against LHRH}

LHRH antiserum (LHRH-AS) was prepared as described previously (Matsuzono et al. 1986). In brief, a castrated goat was immunized against LHRH (NIDDK, Bethesda, MD, USA) conjugated to bovine serum albumin (BSA). The control serum was obtained from a castrated goat immunized against BSA alone.

\section{Experimental design}

LHRH-AS $(0 \cdot 2 \mathrm{ml})$ or control serum $(0 \cdot 2 \mathrm{ml})$ was injected into the jugular vein with the animal under light ether anaesthesia, at $1100 \mathrm{~h}$ on day 4 of the cycle. (In previous studies (Matsuzono et al. 1986), this dose of LHRH-AS completely blocked the preovulatory LH surge and subsequent ovulation, and also induced follicular atresia in the cyclic rat.) Animals were killed, by decapitation, at 6-h intervals from $1100 \mathrm{~h}$ on day 4 (just before the injection) to $60 \mathrm{~h}$ after the treatment, and the ovaries were removed for histological study. Trunk blood was collected into heparinized centrifuge tubes. Blood samples were centrifuged immediately after sampling, and plasma was separated and stored at $-20{ }^{\circ} \mathrm{C}$ until required for hormonal assay.

\section{Radioimmunoassay of $\mathrm{LH}, \mathrm{FSH}$, progesterone and oestradiol-17 $\beta$}

Concentrations of LH and FSH in plasma were measured using NIDDK RIA kits for rat LH and FSH as described

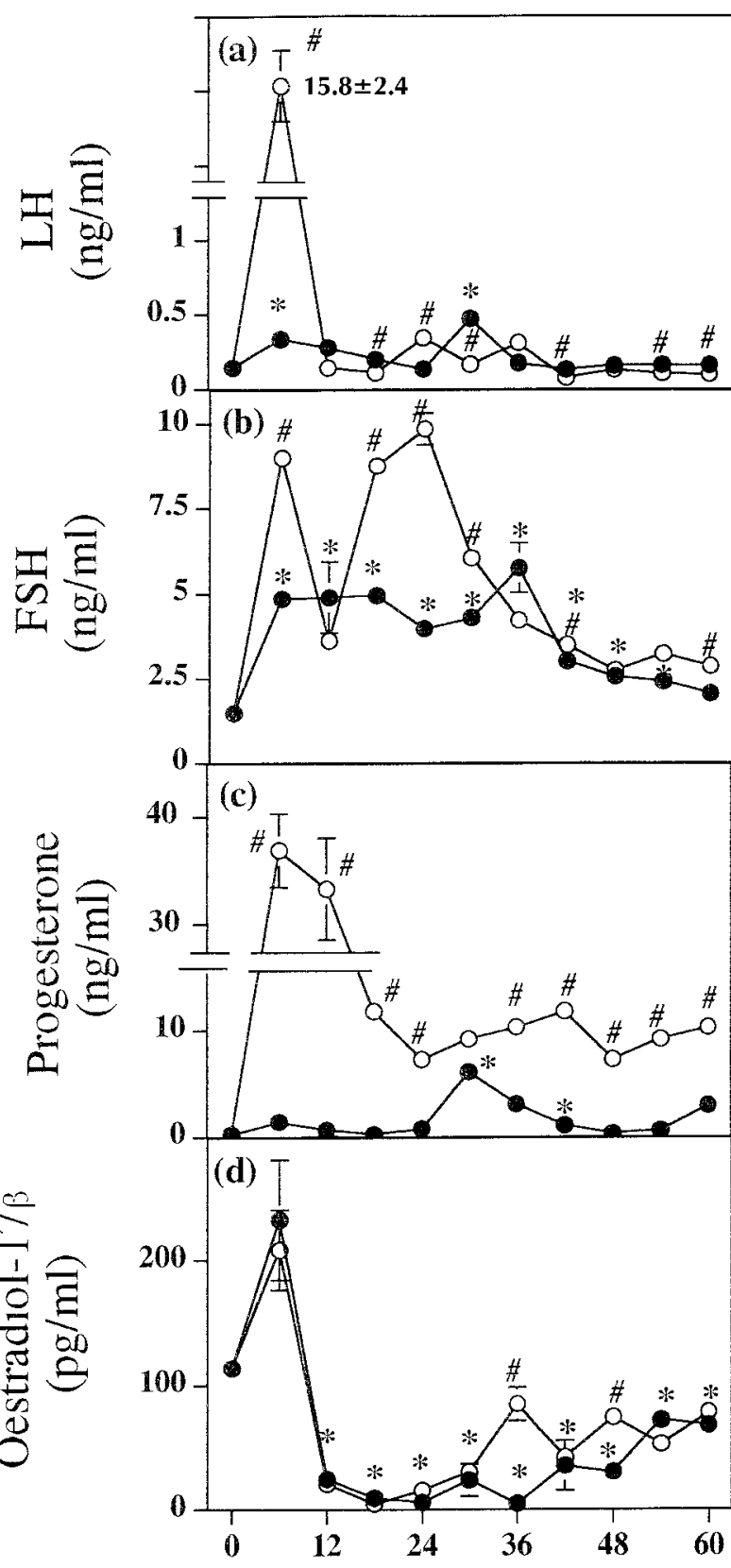

Figure 1 Changes in plasma concentrations of (a) LH, (b) FSH, (c) progesterone and (d) oestradiol- $17 \beta$ after treatment with control serum $(\bigcirc)$ and LHRH-AS treatment $(\mathbf{O})$ at $1100 \mathrm{~h}$ on day 4 of the oestrous cycle. Each value represents the mean \pm S.E.M. of five observations. Significant differences $(P<0 \cdot 05)$ : * ${ }^{*}$ compared with the respective control; \#compared with the value at $1100 \mathrm{~h}$ on day 4 of the oestrous cycle.

previously (Bast \& Greenwald 1974). Iodinated preparations were rat LH-I-5 and FSH-I-5. The antisera used were anti-rat LH-S-9 and anti-rat FSH-S-11. The intraand interassay coefficients of variation were $8.9 \%$ and $6.7 \%$ for $\mathrm{LH}$ and $4 \cdot 4 \%$ and $14 \cdot 6 \%$ for FSH respectively. 


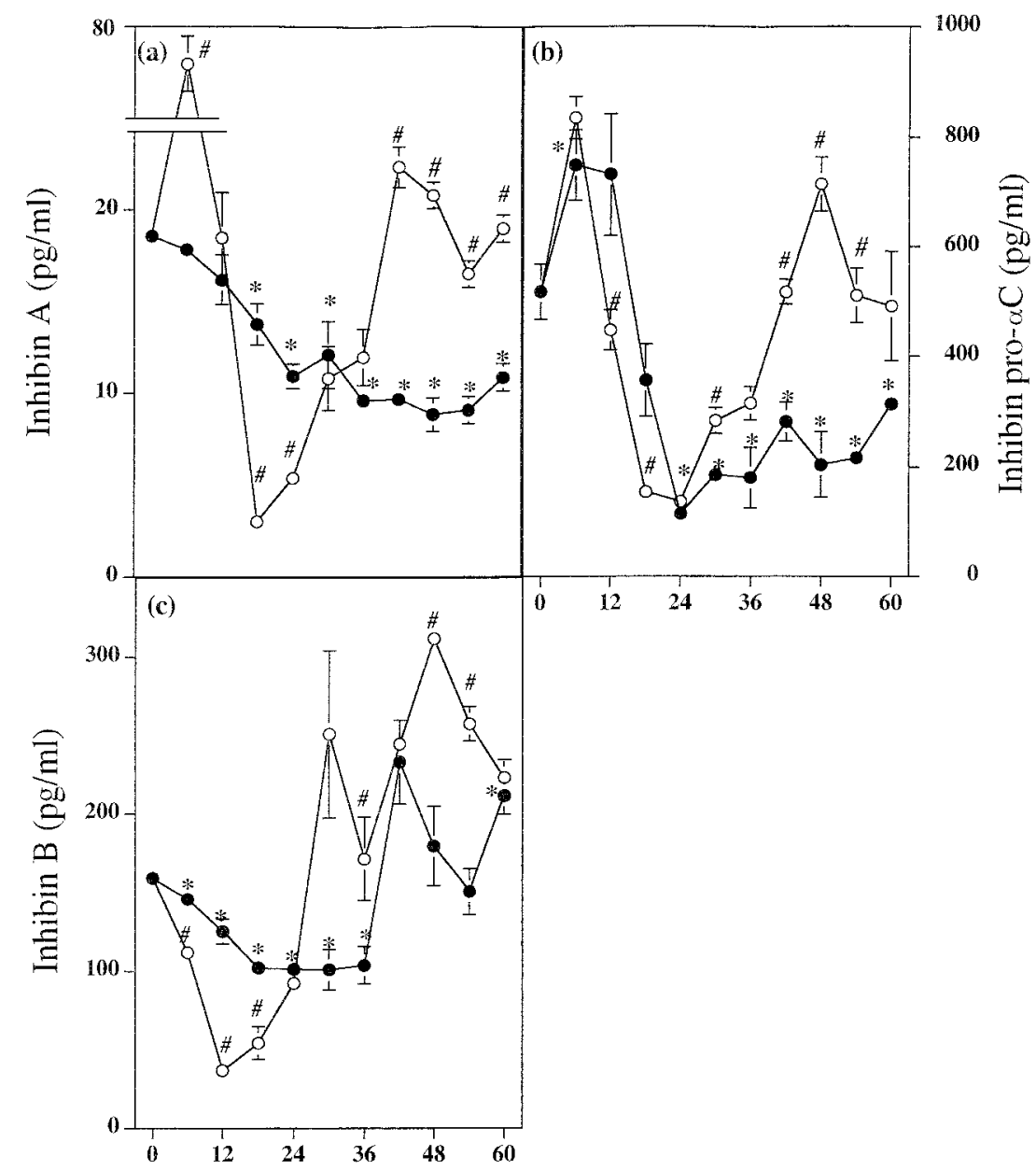

Figure 2 Changes in plasma concentrations of (a) inhibin A, (b) inhibin B and (c) inhibin pro- $\alpha \mathrm{C}$ after treatment with control serum $(\bigcirc)$ and $\mathrm{LHRH}$-AS treatment $(\bullet)$ at $1100 \mathrm{~h}$ on day 4 of the oestrous cycle. Each value represents the mean \pm S.E.M. of five observations. Significant differences $(P<0 \cdot 05)$ : * Compared with the respective control; \#compared with the value at $1100 \mathrm{~h}$ on day 4 of the oestrous cycle.

Concentrations of progesterone and oestradiol-17 $\beta$ in plasma were measured by double-antibody RIA systems using ${ }^{125}$ I-labelled radioligands as described previously (Taya et al. 1985). Antisera against progesterone (GDN 337; Gibori et al. 1977) and oestradiol-17ß (GDN 244; Korenman et al. 1974) were kindly provided by Dr G D Niswender (Colorado State University, Fort Collins, CO, USA). The intra- and interassay coefficients of variation were $6 \cdot 3$ and $15 \cdot 4 \%$ for progesterone and $3 \cdot 7 \%$ and $6 \cdot 2 \%$ for oestradiol- $17 \beta$ respectively.

\section{ELISA of inhibins $A, B$ and pro- $\alpha C$}

Inhibin $\mathrm{A}$, inhibin $\mathrm{B}$ and inhibin pro- $\alpha \mathrm{C}$ assays for human were purchased from Serotec (Oxford, Oxon, UK). The characteristics of these dimer-specific assays for hamster have been described previously (Ohshima et al. 1999). Our previous studies indicated that it is possible to measure the concentration of inhibins $\mathrm{A}, \mathrm{B}$ and pro- $\alpha \mathrm{C}$ in peripheral plasma of the female golden hamster using the human ELISA system. Amounts of inhibins A and B were expressed in terms of recombinant human inhibin A (Groome \& Lawrence 1991) and recombinant human inhibin B (Groome et al. 1996) respectively. The amount of inhibin pro- $\alpha \mathrm{C}$ was expressed in terms of the purified inhibin pro- $\alpha \mathrm{C}$ from human follicular fluid (Groome et al. 1995). The intra- and interassay coefficients of variation are less than $10 \%$ for inhibin $\mathrm{A}$, less than $7 \%$ for inhibin B and less than $20 \%$ for inhibin pro- $\alpha \mathrm{C}$. The sensitivities of the assays for inhibins $\mathrm{A}, \mathrm{B}$ and pro- $\alpha \mathrm{C}$ were $0 \cdot 74 \pm 0 \cdot 10 \mathrm{pg} /$ well $(n=21), 1 \cdot 64 \pm 0 \cdot 14 \mathrm{pg} /$ well $(n=19)$ and $0 \cdot 19 \pm 0 \cdot 03 \mathrm{pg} /$ well $(n=11)$ respectively. 


\section{Ovarian follicular profiles during induced follicular atresia}

To determine the number of large healthy antral follicles in the ovary after induction of follicular atresia, groups of animals were given 10 IU human chorionic gonadotrophin (hCG) (2200 IU/mg; Sankyo Zoki Co., Tokyo, Japan) dissolved in $0.2 \mathrm{ml}$ saline, injected into the jugular vein with the animal under ether anaesthesia, at 6-h intervals after treatment with LHRH-AS $(n=5)$. Animals were killed by decapitation at $18-20 \mathrm{~h}$ after hCG injection, and then the oviducts were examined for oocytes.

\section{Ovarian histology}

Ovaries were fixed in methacarn fixative for $8 \mathrm{~h}$. After fixation, they were dehydrated in alcohol baths, ending in xylene, embedded in paraffin, sectioned serially at $6 \mu \mathrm{m}$ and stained with haematoxylin and eosin for observation of morphological changes during follicular atresia.

\section{Statistics}

All data were expressed as means \pm s.E.M. One-way ANOVA was performed. When variance between two means was uniform, Student's $t$-test was used, but when it was not uniform, the Cochran-Cox test was used. A value of $P<0 \cdot 05$ was considered statistically significant.

\section{Results}

Plasma concentrations of $L H, F S H$, progesterone and oestradiol-17 $\beta$ after LHRH-AS treatment

The preovulatory $\mathrm{LH}$ surge noted at $1700 \mathrm{~h}$ on day 4 in the control animals was completely blocked by the administration of LHRH-AS (Fig. 1a). Plasma concentrations of LH were low throughout the period studied.

Plasma concentrations of FSH increased and reached a plateau within $6 \mathrm{~h}$ after LHRH-AS treatment (Fig. 1b). In the control animals, plateau concentrations were significantly lower than the peak preovulatory values, and the second surge of FSH occurred at $1700 \mathrm{~h}$ on day 4. In treated animals, plasma concentrations of FSH remained relatively high until $36 \mathrm{~h}$ and then gradually decreased until $60 \mathrm{~h}$ after the treatment.

The increase in circulating progesterone noted after the preovulatory LH surge in the control animals did not occur in the animals treated with LHRH-AS. In the latter group, plasma concentrations of progesterone remained low until $24 \mathrm{~h}$, increased abruptly at $30 \mathrm{~h}$, declined gradually until $48 \mathrm{~h}$, and then remained low until $60 \mathrm{~h}$ after the treatment (Fig. 1c).

The profile of oestradiol-17 $\beta$ concentrations after LHRH-AS treatment was similar to that in the control animals. Plasma concentrations of oestradiol $-17 \beta$ reached a peak at $6 \mathrm{~h}$, decreased abruptly to low values within $12 \mathrm{~h}$ after the LHRH-AS treatment, remained low for $36 \mathrm{~h}$, and exhibited a gradual increase thereafter (Fig. 1d).
Table 1 Effects of hCG on hamsters treated with LHRH-AS. Hamsters were injected with LHRH-AS at $1100 \mathrm{~h}$ on day 4 and with $10 \mathrm{IU}$ hCG at various times. The values are mean with or without S.E.M. of tubal oocytes per ovulating animal

\begin{tabular}{cccc} 
& $\begin{array}{l}\text { No. of oocytes/ } \\
\text { ovulating hamster }\end{array}$ & & $\begin{array}{l}\text { Hamsters } \\
\text { hamsters } \\
\text { (No. }(\%))\end{array}$ \\
\cline { 2 - 2 } $\begin{array}{l}\text { Time of hCG injection } \\
\text { (h after LHRH-AS) }\end{array}$ & & \\
0 & $16 \cdot 0 \pm 1 \cdot 1$ & & $5 / 5(100)$ \\
6 & $16 \cdot 3 \pm 4 \cdot 5$ & & $3 / 3(100)$ \\
12 & $13 \cdot 8 \pm 1 \cdot 3$ & $5 / 5(100)$ \\
18 & $11 \cdot 6 \pm 0 \cdot 2^{*}$ & $5 / 5(100)$ \\
24 & $9(13,5)$ & $2 / 5(40)$ \\
30 & 0 & $0 / 5(0)$ \\
36 & $6(11,1)$ & $2 / 5(40)$ \\
42 & $11 \cdot 3 \pm 2 \cdot 2$ & $3 / 5(60)$ \\
48 & $5 \cdot 3 \pm 3 \cdot 4^{*}$ & $3 / 5(60)$ \\
54 & $6 \cdot 8 \pm 1 \cdot 5^{*}$ & $5 / 5(100)$ \\
60 & $9 \cdot 8 \pm 1 \cdot 5$ & $5 / 5(100)$
\end{tabular}

${ }^{*}$ Statistically $(P<0.05)$ different from the values at the time of LHRH-AS injection $(0 \mathrm{~h})$.

\section{Plasma concentrations of inhibins after LHRH-AS treatment}

Different concentration profiles were observed for circulating inhibins $\mathrm{A}, \mathrm{B}$ and pro- $\alpha \mathrm{C}$ after a single administration of LHRH-AS. The preovulatory inhibin A surge, usually noted at $1700 \mathrm{~h}$ on day 4 in the control animals, was completely blocked by LHRH-AS treatment. Plasma concentrations of inhibin A decreased to $58.6 \%$ of initial values by $24 \mathrm{~h}$ after LHRH-AS treatment and then remained low throughout the remaining period of study (Fig. 2a).

Plasma concentrations of inhibin B decreased to $64 \cdot 2 \%$ of the initial value within $18 \mathrm{~h}$ and remained low until $36 \mathrm{~h}$ (Fig. 2b), after which they increased abruptly to greater than the initial values, $42 \mathrm{~h}$ after the LHRH-AS treatment. These greater concentrations were maintained throughout the remainder of the experimental period. Changes in plasma concentrations of inhibin $\mathrm{B}$ were negatively correlated with the changes in FSH $(r=-0 \cdot 516 ; n=55)$.

Plasma concentrations of inhibin pro- $\alpha \mathrm{C}$ increased and remained high until $12 \mathrm{~h}$ after LHRH-AS treatment (Fig. 2c). Thereafter, they declined abruptly and reached a nadir $(21.9 \%$ of initial values) at $24 \mathrm{~h}$, followed by a gradual increase up to $60 \mathrm{~h}$ after LHRH-AS treatment.

\section{Ovarian follicular profiles during induced follicular atresia}

Table 1 gives details of the ovarian response to hCG in animals treated with LHRH-AS. The number of ovulations in response to hCG decreased significantly at $18 \mathrm{~h}$ after the LHRH-AS treatment as compared with that at time 0 . No ovulatory response to hCG was noted at $30 \mathrm{~h}$ 

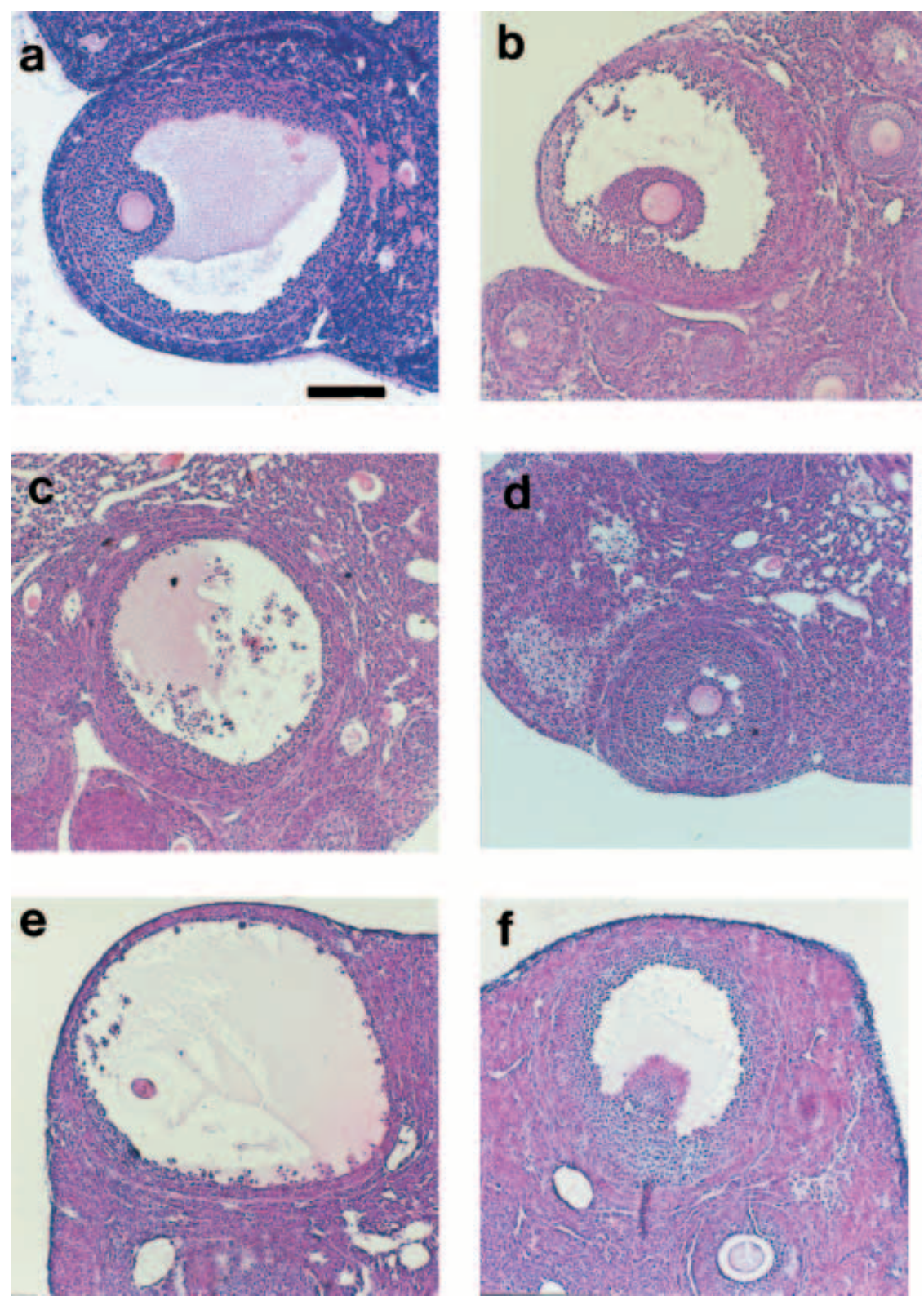

Figure 3 Time-related morphological changes in antral follicles in the ovary during induced follicular atresia by treatment with LHRH-AS, in the golden hamster. Healthy antral follicles at $0 \mathrm{~h}(\mathrm{a}), 42 \mathrm{~h}(\mathrm{~d})$ and $60 \mathrm{~h}(\mathrm{f})$, and atretic antral follicles at $24 \mathrm{~h}(\mathrm{~b}), 42 \mathrm{~h}$ (c) and $60 \mathrm{~h}$ (e) after LHRH-AS treatment at $1100 \mathrm{~h}$ on day 4 of the oestrous cycle were stained with haematoxylin and eosin. Bar represents $150 \mu \mathrm{m}$; all sections are shown at the same magnification.

after the LHRH-AS treatment, but the rate of ovulation and the number of ovulations gradually recovered from $36 \mathrm{~h}$ after the treatment.

\section{Ovarian histology}

Morphological changes in the ovary in response to LHRH-AS are shown in Figure 3. Healthy large pre- ovulatory follicles were present in ovaries at $1100 \mathrm{~h}$ on day $4(0 \mathrm{~h})$. At $24 \mathrm{~h}$ after LHRH-AS treatment, early atretic preovulatory follicles were to be seen in the ovaries, and at $42 \mathrm{~h}$ after LHRH-AS treatment, new healthy antral follicles were observed, with advanced atretic preovulatory follicles in the ovary. At $60 \mathrm{~h}$ after LHRH-AS treatment, the number of new antral follicles was further increased, with atresia of preovalatory follicles. 


\section{Discussion}

The present study clearly demonstrates that the secretory patterns of dimeric inhibin (inhibins A and B) and inhibin pro- $\alpha \mathrm{C}$ are different from each other during the period of follicular atresia and the subsequent follicular development induced by LHRH-AS. In this study, atretic follicles were present in ovaries $24 \mathrm{~h}$ after the LHRH-AS treatment given at $1100 \mathrm{~h}$ on day 4 of the oestrous cycle (Fig. 3). During the first $18 \mathrm{~h}$ after LHRH-AS treatment, plasma concentrations of dimeric inhibins decreased, whereas plasma concentrations of inhibin pro- $\alpha \mathrm{C}$ increased at $6 \mathrm{~h}$ after LHRH-AS treatment. Our findings in a previous study indicated that a decline in the secretion of oestradiol$17 \beta$ from antral follicles was an early sign of follicular atresia (Otsuka et al. 1997). Uilenbroek et al. (1998) have also reported that a rapid decline in the ability of preovulatory follicles to secrete oestradiol-17 $\beta$ in vitro appeared to be an early sign of atresia. In the present study, plasma concentrations of oestradiol-17 $\beta$ remained high until $6 \mathrm{~h}$ and declined abruptly at $12 \mathrm{~h}$ after the treatment, corresponding with the changes in the number of follicles in response to hCG, which suggests that follicles became atretic from $6 \mathrm{~h}$ to $12 \mathrm{~h}$ after LHRH-AS treatment. The decline in plasma inhibin pro- $\alpha \mathrm{C}$ after treatment with LHRH-AS was delayed by $6-12 \mathrm{~h}$ as compared with that of oestradiol-17 $\beta$, suggesting that inhibin pro- $\alpha \mathrm{C}$ is secreted not only from healthy follicles but also from early atretic antral follicles. Immunohistochemical localization of the inhibin $\alpha$ subunit in early atretic follicles observed in our previous studies (Otsuka et al. 1997) also supports this hypothesis.

Dimeric inhibins are secreted mainly from granulosa cells of antral follicles in the hamster ovary during the oestrous cycle (Kishi et al. 1995, Ohshima et al. 1999). In the present study, plasma concentrations of inhibin A did not recover completely from the decline during the experimental period, whereas those of inhibin B recovered by $42 \mathrm{~h}$ after the LHRH-AS treatment, when new antral follicles were present. Furthermore, changes in inhibin A were associated with changes in the ovulatory response of follicles to hCG throughout the experiment. In addition, a surge of inhibin A, noted at $1700 \mathrm{~h}$ on day 4 in the control animals, disappeared with blockade of the LH surge after LHRH-AS treatment, suggesting that the LH surge may induce a preovulatory surge of inhibin A. Greenwald (1967) demonstrated that the number of follicles larger than $415 \mu \mathrm{m}$ in diameter had a relationship with the number of ovulations induced by hCG throughout pregnancy in the hamster. These results indicate that inhibin $\mathrm{A}$ is mainly secreted from mature preovulatory follicles. This view is also supported by our previous study showing that the changes in plasma concentrations of inhibin $\mathrm{A}$ reflect the number of large antral follicles in the ovary (Ohshima et al. 1999). In the present study, plasma concentrations of inhibin B recovered earlier than those of inhibin A. Kishi et al. $(1995,1997 b)$ have reported that inhibin has a major role in regulating the ovulation rate in the hamster through the control of FSH secretion. The secondary FSH surge starts to decrease with increases in inhibin A and inhibin B in the normal oestrous cycle of the cyclic hamster (Ohshima et al. 1999). In the present study, however, inhibin B alone increased when plasma concentrations of FSH decreased. A significant negative relationship between the pattern of FSH and inhibin B in the plasma was also observed. These results suggest that inhibin B secreted from small antral follicles might play a major role in suppressing the secondary FSH surge in the cyclic hamster.

In the current study, plasma concentrations of progesterone increased abruptly at $30 \mathrm{~h}$ after LHRH-AS treatment, and no ovulatory response to hCG injected at this time was noted during this period. Hubbard \& Greenwald (1981) demonstrated that, after atresia was induced in antral follicles of hypophysectomized pregnant mare's serum gonadotrophin (PMSG)-treated hamsters by an injection of PMSG antiserum, serum progesterone showed a sharp increase. These results suggest that atretic follicles secrete progesterone.

\section{Conclusions}

The present data suggest that inhibin A is mainly secreted by mature preovulatory follicles, whereas inhibin $\mathrm{B}$ is secreted by small and large antral follicles. Inhibin pro- $\alpha \mathrm{C}$ is secreted from not only healthy follicles, but also from early atretic antral follicles.

\section{Acknowledgements}

We are grateful to Dr A F Parlow, and the Rat Pituitary Hormone Distribution Program, NIDDK, NIH, USA for RIA materials and LHRH; thanks are also due to Dr G D Niswender, Colorado State University, Fort Collins, CO, USA for antisera to progesterone (GDN 337) and oestradiol-17 $\beta$ (GDN 224). We express our gratitude to Dr Chandana B Herath of our laboratory and Dr Brian K Petroff of the University of Kansas Medical Center, Kansas City, KA, USA for reading the original manuscript and offering valuable suggestions. This work was supported in part by a US-Japan cooperative Research Grant from the Japan Society for Promotion of Science.

\section{References}

Bast JD \& Greenwald GS 1974 Serum profiles of follicle-stimulating hormone, luteinizing hormone and prolactin during the estrus cycle of the hamster. Endocrinology 94 1295-1299.

Gibori G, Antczak E \& Rothchild I 1977 The role of estrogen in regulation of luteal progesterone secretion in the rat after day 12 of pregnancy. Endocrinology 100 1483-1495. 
Greenwald GS 1967 Induction of ovulation in the pregnant hamster. American Journal of Anatomy 121 249-258.

Groome N \& Lawrence 1991 Preparation of monoclonal antibodies reacting with $\beta$ A subunit of human ovarian inhibin. Hybridoma 40 717-723.

Groome NP, Illingworth JP, O’Brien M, Priddle J, Weaver K \& McNeilly AS 1995 Quantification of inhibin pro- $\alpha$ C-containing forms in human serum by a new ultrasensitive two-site enzymelinked immunosorbent assay. Journal of Clinical Endocrinology and Metabolism 80 2926-2932.

Groome NP, Illingworth PJ, O’Brien, Pai R, Rodger FE, Mather JP \& McNeilly AS 1996 Measurement of dimeric inhibin B throughout the human menstrual cycle. Journal of Clinical Endocrinology and Metabolism 81 1401-1405.

Hubbard CJ \& Greenwald GS 1981 Changes in DNA, cyclic nucleotides and steroids during induced follicular atresia in the hamster. Journal of Reproduction and Fertility 63 455-461.

Kaneko H, Taya K \& Sasamoto S 1987 Changes in the secretion of inhibin and steroid hormones during induced follicular atresia after hypophysectomy in the rat. Life Sciences 41 1823-1830.

Kishi H, Taya K, Watanabe G \& Sasamoto S 1995 Follicular dynamics and secretion of inhibin and oestradiol-17 $\beta$ during the oestrous cycle of the hamster. Journal of Endocrinology 146 169-176.

Kishi H, Okada T, Otsuka M, Watanabe G, Taya K \& Sasamoto S 1996 Induction of superovulation by immunoneutralization of endogenous inhibin through the increase in the secretion of follicle-stimulating hormone in the cyclic golden hamster. Journal of Endocrinology 151 65-75.

Kishi H, Kondo M, Arai K, Watanabe G \& Taya K 1997a Involvement of ovarian inhibin and steroid hormones in the regulation of follicle stimulating hormone (FSH) and luteinizing hormone (LH) secretion during pseudopregnancy in the rat. Journal of Reproduction and Development 43 243-250.

Kishi H, Okada T, Kawazu S, Otsuka M, Taya K, Watanabe G \& Sasamoto S $1997 b$ Effects of passive immunization against oestradiol-17 $\beta$ and inhibin on the secretion of gonadotrophin in the cyclic golden hamster (Mesocricetus auratus). Reproduction, Fertility and Development 9 447-453.

Korenman SG, Stevens RH, Carpenter LA, Robb M, Nisswender GD \& Sherman BM 1974 Estradiol radioimmunoassay without chromatography: procedure, validation and normal values. Journal of Clinical Endocrinology and Metabolism 38 718-720.

Matuzono N, Taya K, Watanabe G \& Sasamoto S 1986 Initiation of ovarian follicular maturation without a surge of FSH in cyclic rats with antiserum to LH-releasing hormone. Journal of Endocrinology $110279-285$.

Ohshima K, Kishi H, Itoh M, Arai K, Uehara K, Groome NP \& Taya K 1999 Secretion of inhibin A, inhibin B and inhibin pro- $\alpha \mathrm{C}$ during the oestrous cycle of the golden hamster (Mesocricetus auratus). Journal of Endocrinology 162 451-456.

Otsuka M, Kishi H, Arai K, Watanabe G, Taya K \& Greenwald GS 1997 Temporal changes in inhibin, steroid hormones, and steroidogenic enzymes during induced follicular atresia in the hypophysectomized cyclic hamster. Biology of Reproduction $\mathbf{5 6}$ 423-429.

Taya K \& Watanabe G 1999 Inhibin as a key hormone in determing species-specific ovulation rates in mammals. In Recent Progress in Molecular and Comparative Endocrinology, pp 134-143. Eds HB Kwon, JMP Joss \& S Ishii. Korea: Hormone Research Center.

Taya K, Watanabe G \& Sasamoto S 1985 Radioimmunoassay for progesterone, testosterone and estradiol-17 $\beta$ using 125Iiodohistamine radioligands. Japanese Journal of Animal Reproduction 31 186-197.

Uilenbroek JTJ, Durlinger ALL, Tebar M, Kramer P, van Schaik RHN, Wierikx CDJ \& de Jong FH 1998 Temporal changes in inhibin subunit mRNAs during atresia of preovulatory follicles in the rat. Journal of Endocrinology 159 331-340.

Received 31 October 2001

Accepted 16 November 2001 